\title{
Comparison of Follow-Up Length-Matched Single-Center Myelomeningocele Postnatal Closure Cohort to the Management of Myelomeningocele Study (MOMS) Trial Results
}

\author{
Kristin J. Weaver ${ }^{a}$ Michael M. McDowell ${ }^{b}$ Michael D. White ${ }^{c}$ \\ Zachary J. Tempel $^{d}$ Nathan T. Zwagerman ${ }^{e}$ Christopher P. Deibert $^{f}$ \\ Christopher M. Bonfield ${ }^{g}$ Stephen Johnson ${ }^{\text {h }}$ Stephanie Greene ${ }^{b}$ \\ aDepartment of Neurosurgery, University of Mississippi Medical Center, Jackson, MS, USA; 'bepartment of \\ Neurosurgery, Children's Hospital of Pittsburgh University of Pittsburgh Medical Center, Pittsburgh, PA, USA; \\ 'Department of Neurosurgery, Barrow Neurological Institute, Phoenix, AZ, USA; ${ }^{\mathrm{d}}$ Mayfield Brain and Spine, \\ Cincinnati, $\mathrm{OH}, \mathrm{USA}$; ${ }^{\mathrm{e}}$ Department of Neurosurgery, Medical College of Wisconsin, Milwaukee, WI, USA; ${ }^{\mathrm{f}}$ Department \\ of Neurosurgery, Emory University, Atlanta, GA, USA; ${ }^{9}$ Department of Neurosurgery, Vanderbilt University, Nashville, \\ TN, USA; hDepartment of Neurosurgery, Rutgers University, Newark, NJ, USA
}

\section{Keywords}

Myelomeningocele $\cdot$ Postnatal · Prenatal $\cdot$ Hydrocephalus · Chiari II Shunt · Ambulation

\begin{abstract}
Objective: We sought to compare our large single-institution cohort of postnatal myelomeningocele closure to the 2 arms of the Management of Myelomeningocele Study (MOMS) trial at the designated trial time points, as well as assess outcomes at long-term follow-up among our postnatal cohort. Methods: A single-institutional retrospective review of myelomeningocele cases presenting from 1995 to 2015 at Children's Hospital of Pittsburgh was performed. We compared outcomes at 12 and 30 months to both arms of the MOMS trial and compared our cohort's outcomes at those designated time points to our long-term outcomes. Univariate statistical analysis was performed as appropriate. $\boldsymbol{R e}$ sults: One-hundred sixty-three patients were included in this study. All patients had at least 2-year follow-up, with a mean follow-up of 10 years (range 2-20 years). There was no
\end{abstract}

karger@karger.com

(c) 2021 S. Karger AG, Basel

www.karger.com/pne

Karger" difference in the overall distribution of anatomic level of defect. Compared to our cohort, the prenatal cohort had a higher rate of tethering at 12 months of age, 8 versus $1.8 \%$. Conversely, the Chiari II decompression rate was higher in our cohort (10.4 vs. 1.0\%). At 30 months, the prenatal cohort had a higher rate of independent ambulation, but our cohort demonstrated the highest rate of ambulation with or without assistive devices among the 3 groups. When comparing our cohort at these early time points to our long-term followup data, our cohort's ambulatory function decreased from 84 to $66 \%$, and the rate of detethering surgery increased almost 10-fold. Conclusions: This study demonstrated that overall ambulation and anatomic-functional level were significantly better among our large postnatal cohort, as well as having significantly fewer complications to both fetus and mother, when compared to the postnatal cohort of the MOMS trial. Our finding that ambulatory ability declined significantly with age in this patient population is worrisome for the long-term outcomes of the MOMS cohorts, especially given the high rates of cord tethering at early ages within the prenatal cohort. These findings suggest that the perceived 
benefits of prenatal closure over postnatal closure may not be as substantial as presented in the original trial, with the durability of results still remaining a concern.

() 2021 S. Karger AG, Basel

\section{Introduction}

The standard management of myelomeningocele has traditionally been postnatal closure within several days of birth. A study of 29 infants who underwent in utero closure of myelomeningocele was published in 1999 [1], reporting a decrease in the rate of ventriculoperitoneal shunt placement in infants who underwent prenatal closure versus historical controls. In 2011, the Management of Myelomeningocele Study (MOMS) trial, a prospective randomized controlled trial supported by the National Institutes of Health, was published [2]. They reported many benefits of prenatal closure, including a decrease in the rate of shunt placement and improvements in cognitive outcomes, motor function, and hindbrain herniation with up to 30 months of follow-up. However, there were trends towards increased cord tethering and wound dehiscence in the prenatal group, as well as complications such as preterm delivery and uterine dehiscence.

Recently, the Congress of Neurologic Surgeons (CNS), Section of Pediatric Neurologic Surgeons of the American Association of Neurologic Surgeons (AANS), and Spina Bifida Association (SBA) published guidelines regarding the management of myelomeningocele [3]. In short, the guidelines support prenatal repair to reduce the risk of developing shunt-dependent hydrocephalus (level I recommendation). The guidelines committee found on literature review that prenatal closure may improve short-term ambulatory status (level II), but development of tethered cord in both prenatal and postnatal groups is associated with loss of ambulation (level III recommendation), with a slightly higher rate of tethered cord syndrome and/or inclusion cyst in the prenatal group (level II recommendation).

In addition to the maternal and neonatal complications inherent to in utero closure, some of the largest concerns about the MOMS trial are generalizability and durability. The goal of this study is to add to the growing body of literature regarding outcomes of postnatal closure and to compare our single-institutional myelomeningocele cohort to the prenatal and postnatal closure groups of the MOMS trial at the designated trial time points to address the question of generalizability, as well as to institutional long-term follow-up data to address the durability question.

\section{Methods}

A single-institutional retrospective review of all myelomeningocele cases presenting from 1995 to 2015 at Children's Hospital of Pittsburgh was performed with Institutional Review Board approval. All myelomeningoceles were closed postnatally. Patients with prenatal closure, conditions such as meningoceles or myelocystoceles, or those with insufficient follow-up ( $<2$ years) were excluded from this study. The following data were collected: gestational age at birth, gender, birth weight, anatomic level, anatomicfunctional level (the anatomic level was defined by imaging [X-ray, $\mathrm{CT}$, or MRI]; the functional level was defined as the lowest level of purposeful lower extremity movement at 24 months of age), shunting, shunt infection, detethering surgery, Chiari II decompression surgery, death, and ambulation status. The criteria used for ventriculoperitoneal shunt placement were identical to the criteria from the MOMS trial: increasing head circumference crossing the 97th percentile for gestational age, progressive ventriculomegaly on serial ultrasound, splaying of sutures, setting sun sign, bulging anterior fontanelle, or pseudomeningocele formation at the surgical closure site. These findings were used to define symptomatic hydrocephalus requiring shunt placement. A patient's need for Chiari II decompression surgery was similar in both our cohort and the MOMS trial cohorts. This included assessment for shunted patients with new or recurrent symptoms (stridor, vocal cord paralysis, swallowing difficulties, and central apnea) in the absence of shunt failure with radiologic studies indicating the presence of Chiari II malformation. Patients with an inconclusive workup underwent empirical shunt exploration prior to Chiari II decompression surgery. Detailed criteria for assessing a patient's need for Chiari decompression are further outlined in our group's previous study [4]. We also studied maternal characteristics when available (49.7\%) including maternal age, body mass index, gestational diabetes, pre-eclampsia, oligohydramnios, placental abruption, spontaneous labor, spontaneous membrane rupture, transfusion requirement, chorioamnionitis, chorioamniotic membrane separation, and pulmonary edema. We compared the outcomes at 12 and 30 months to both arms of the MOMS trial, as well as comparing our cohort's outcomes at those designated time points to our longterm outcomes. As in the MOMS trial, the anatomic-functional level was defined as comparing the functional to anatomic levels and reporting as " 2 or more better," "1 better," "no better," "1 worse," and " 2 or more worse." Univariate analysis using $\chi^{2}$, Fisher's exact, Mann-Whitney, and McNemar's tests was performed to evaluate the differences between the groups as appropriate. A $p$ value of $<0.05$ was considered to be statistically significant. Standard statistical processing software was used to perform the analyses (SAS version 9.4; Cary, NC, USA).

\section{Results}

A total of 163 patients were included in the study. The mean length of follow-up was 10 years (range 2-22 years). There was a total of 8 deaths (5\%) in our cohort, with 5 (3\%) occurring in the first year of life and 3 in children older than 5 years of age (ages 6-12). None of the deaths were secondary to direct complications from their post- 
Fig. 1. Distribution of the anatomic-functional level of the UPMC cohort compared to the prenatal and postnatal MOMS groups.

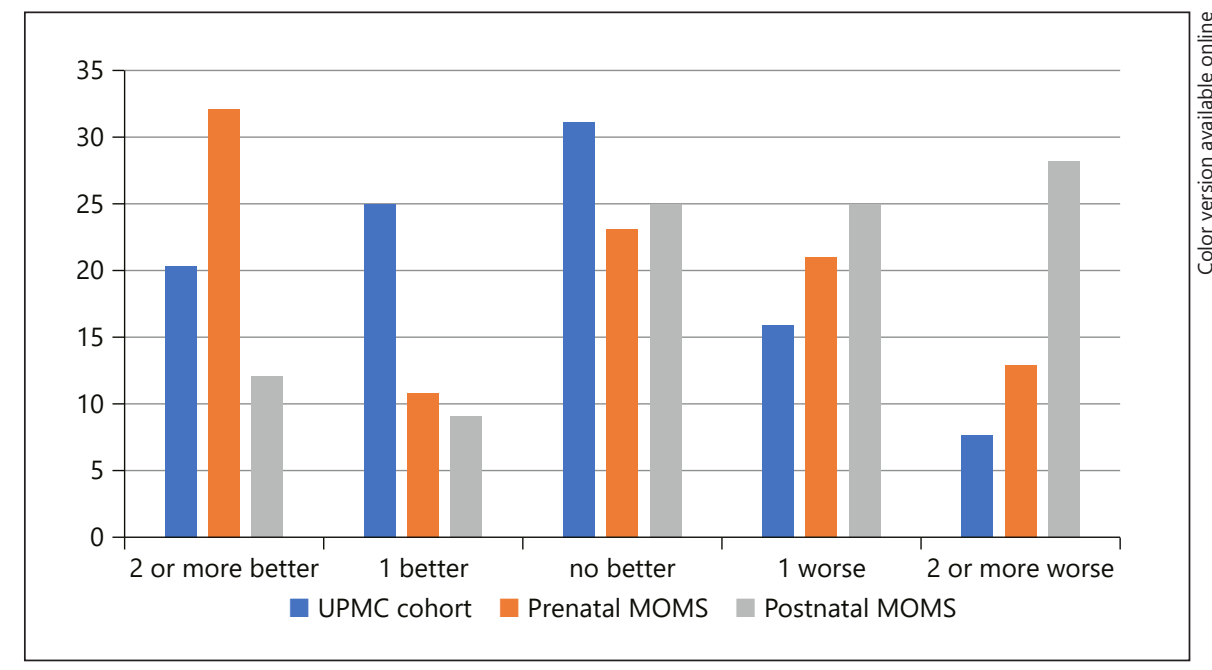

Table 1. Patient characteristics of the UPMC cohort and MOMS prenatal and postnatal cohorts

\begin{tabular}{|c|c|c|c|c|c|}
\hline & $\begin{array}{l}\text { UPMC } \\
\text { cohort }\end{array}$ & $\begin{array}{l}\text { Prenatal } \\
\text { MOMS }\end{array}$ & $p$ value & $\begin{array}{l}\text { Postnatal } \\
\text { MOMS }\end{array}$ & $p$ value \\
\hline Gestational age, weeks & $37.4 \pm 2.14$ & $34.1 \pm 3.1$ & $<0.0001$ & $37.3 \pm 1.1$ & 0.69 \\
\hline Age $<30$ weeks, $n / N(\%)$ & $2 / 160(1.3)$ & $10 / 78(13)$ & 0.0003 & $0 / 80(0)$ & 0.55 \\
\hline Age $\geq 30$ and $<35$ weeks, $n / N(\%)$ & $11 / 160(6.8)$ & $26 / 78(33.3)$ & $<0.0001$ & $4 / 80(5)$ & 0.78 \\
\hline Age $\geq 35$ weeks, $n / N(\%)$ & $147 / 160(91.9)$ & $42 / 78(54)$ & $<0.0001$ & $76 / 80(95)$ & 0.44 \\
\hline Age $\geq 37$ weeks, $n / N(\%)$ & $129 / 160(80.6)$ & $16 / 78(21)$ & $<0.0001$ & $68 / 80(85)$ & 0.48 \\
\hline \multicolumn{6}{|l|}{ Gender, $n / N(\%)$} \\
\hline Male & $79 / 163(48.5)$ & $43 / 78(55)$ & 0.33 & $29 / 80(36)$ & 0.071 \\
\hline Female & $84 / 163(51.5)$ & $35 / 78(45)$ & & $51 / 80(64)$ & \\
\hline Birth weight, $g$ & $3,091 \pm 634$ & $2,383 \pm 688$ & $<0.0001$ & $3,039 \pm 469$ & 0.52 \\
\hline \multicolumn{6}{|l|}{ Anatomic level, $n / N(\%)$} \\
\hline Thoracic & $10 / 157(6.4)$ & $4 / 78(5)$ & 0.31 & $3 / 80(4)$ & 0.27 \\
\hline $\mathrm{L} 1-\mathrm{L} 2$ & $23 / 157(14.6)$ & $21 / 78(27)$ & & $10 / 80(12)$ & \\
\hline L3-L4 & $65 / 157(41.4)$ & $30 / 78(38)$ & & $45 / 80(56)$ & \\
\hline L5-S1 & $59 / 157(37.6)$ & $23 / 78(29)$ & & $22 / 80(28)$ & \\
\hline \multicolumn{6}{|l|}{ Anatomic-functional level, $n / N(\%)$} \\
\hline 2 or more better & $32 / 157(20.4)$ & $20 / 62(32)$ & 0.046 & $8 / 67(12)$ & 0.12 \\
\hline 1 better & $39 / 157(24.8)$ & $7 / 62(11)$ & & $6 / 67(9)$ & \\
\hline No better & $49 / 157(31.2)$ & $14 / 62(23)$ & & $17 / 67(25)$ & \\
\hline 1 worse & $25 / 157(15.9)$ & $13 / 62(21)$ & & $17 / 67(25)$ & \\
\hline 2 or more worse & $12 / 157(7.6)$ & $8 / 62(13)$ & & $19 / 67(28)$ & \\
\hline Any worsened anatomic-functional level, $n / N(\%)$ & $37 / 157(23.6)$ & $21 / 62(34)$ & $<0.0001$ & $36 / 67(53)$ & $<0.0001$ \\
\hline
\end{tabular}

Bold values indicate $p<0.05$.

natal closure. Deaths within the first year of life were associated with severe central sleep apnea since birth as well as comorbid conditions, including cranial nerve dysfunction, sepsis (unrelated to wound or shunt complications) from an abdominal compartment syndrome, and hepatic dysfunction. The deaths in older children were secondary to respiratory events or worsening syringobulbia and brainstem compression in the setting of tracheostomy dependence. Our group's previous work further details the patient deaths from this cohort [4]. The gestational age for our cohort ( 37.4 weeks) at birth was comparable to the postnatal MOMS cohort and significantly older than the prenatal MOMS cohort (34.1 weeks, $p<0.0001$ ) (Table 1). The breakdown of the gestational age at time of 
Table 2. Results at 12-month follow-up of the UPMC cohort compared to MOMS trial data

\begin{tabular}{lccccc}
\hline & $\begin{array}{l}\text { UPMC } \\
\text { cohort }\end{array}$ & $\begin{array}{l}\text { Prenatal } \\
\text { surgery }\end{array}$ & $p$ value & $\begin{array}{l}\text { Postnatal } \\
\text { surgery }\end{array}$ & $p$ value \\
\hline Shunting by 12 months, $n / N(\%)$ & $134 / 156(85.9)$ & $31 / 78(40)$ & $<\mathbf{0 . 0 0 0 1}$ & $66 / 80(82)$ & 0.57 \\
Shunt infections by 12 months, $n / N(\%)$ & $14 / 134(10.5)$ & $5 / 31(16.1)$ & 0.37 & $7 / 66(10.6)$ & 0.97 \\
Detethering by 12 months, $n / N(\%)$ & $3 / 163(1.8)$ & $6 / 77(8)$ & $\mathbf{0 . 0 3 2}$ & $1 / 80(1)$ & 0.73 \\
Chiari decompression by 12 months, $n / N(\%)$ & $17 / 163(10.4)$ & $1 / 77(1)$ & $\mathbf{0 . 0 1 5}$ & $4 / 80(5)$ & 0.22 \\
\hline
\end{tabular}

Bold values indicate $p<0.05$.

Table 3. Results at 30-month follow-up of the UPMC cohort compared to MOMS trial data

\begin{tabular}{llllll}
\hline & $\begin{array}{l}\text { UPMC } \\
\text { cohort }\end{array}$ & $\begin{array}{l}\text { Prenatal } \\
\text { surgery }\end{array}$ & $p$ value & $\begin{array}{l}\text { Postnatal } \\
\text { surgery }\end{array}$ & $p$ value \\
\hline $\begin{array}{l}\text { Death by } 30 \text { months, } n / N(\%) \\
\text { Ambulatory ability at 30 months, } n / N(\%)\end{array}$ & $5 / 163(3.1)$ & $3 / 77(3.9)$ & 0.62 & $3 / 80(3.8)$ & 0.75 \\
$\quad$ Independent & $39 / 154(25.3)$ & $26 / 62(42)$ & $\mathbf{0 . 0 0 0 5}$ & $14 / 67(21)$ & $<\mathbf{0 . 0 0 0 1}$ \\
$\quad$ With assistance & $90 / 154(58.4)$ & $18 / 62(29)$ & & $24 / 67(36)$ & \\
$\quad$ None & $25 / 154(16.3)$ & $18 / 62(29)$ & & $29 / 67(43)$ & \\
Ambulatory independence, $n / N(\%)$ & $39 / 154(25.3)$ & $26 / 62(42)$ & $\mathbf{0 . 0 1 6}$ & $14 / 67(21)$ & 0.48 \\
Any ambulatory ability, $n / N(\%)$ & $129 / 154(83.7)$ & $44 / 62(71)$ & $\mathbf{0 . 0 0 0 5}$ & $38 / 67(57)$ & $<\mathbf{0 . 0 0 0 1}$ \\
\hline
\end{tabular}

Bold values indicate $p<0.05$.

birth into the following categories: $<30,30-35,>35$, and $>37$ weeks is listed in Table 1 . Similarly, the birth weight of our cohort was comparable to the postnatal MOMS group; the birth weight of the prenatal MOMS group was significantly less, as expected with younger gestational age at birth $(3,091$ vs. $2,383 \mathrm{~g} ; p<0.0001)$. There were no differences in gender or the distribution of the anatomic level of the myelomeningocele in our cohort compared to either arm of the MOMS trial. Table 1 and Figure 1 show the distribution of the anatomic-functional level of our cohort in comparison with the prenatal and postnatal MOMS groups. When analyzing specifically the worsened anatomic-functional level (including both the "1 worse" or " 2 or more worse" groups), our cohort has significantly fewer patients with a worse functional level compared to the anatomic level (23.6\%) in comparison with both the prenatal $(34 \% ; p<0.0001)$ and postnatal $(53 \% ; p<0.0001)$ MOMS cohorts.

One of the primary outcomes of the MOMS trial was placement of a shunt, and they showed a significant decrease in the number of patients who received a shunt by 12 months in the prenatal compared to the postnatal cohort. Our cohort had very similar results compared to the postnatal cohort of the MOMS trial. $85.9 \%$ of our patients were shunted, compared to $40 \%$ of the prenatal group and $82 \%$ of the postnatal group (Table 2). The risk of shunt infection by 12 months for our cohort was not statistically different in comparison with either arm of the MOMS trial (Table 2). The rate of surgery for a tethered cord in our cohort (1.8\%) was similar to the postnatal MOMS group ( $1 \% ; p=0.73)$ and significantly less than the prenatal MOMS group $(8 \% ; p=0.032)$ (Table 2). Lastly, our cohort had a significantly higher number of patients who underwent a Chiari II decompression by 12 months compared to the prenatal MOMS cohort ( $p=$ 0.015 ). There was no statistically significant difference between our cohort and the postnatal MOMS cohort (Table 2).

Another primary outcome of the MOMS trial was ambulatory status at 30 months. Table 3 and Figure 2 show the distribution of ambulatory status of our cohort compared to the MOMS trial. There was a greater rate of independent ambulation in the prenatal MOMS group (42\%) compared to our cohort $(25.3 \% ; p=0.016)$ and a similar rate of independent ambulation in the postnatal MOMS group compared to our cohort (21\%; $p=0.48)$. However, when looking at "any ambulation" status, which included independent ambulation and ambulation 
Table 4. Maternal characteristics and complications of the UPMC cohort compared to MOMS trial data

\begin{tabular}{lccccc}
\hline & $\begin{array}{l}\text { UPMC } \\
\text { cohort }\end{array}$ & $\begin{array}{l}\text { Prenatal } \\
\text { surgery }\end{array}$ & $p$ value & $\begin{array}{l}\text { Postnatal } \\
\text { surgery }\end{array}$ & $p$ value \\
\hline Maternal age, years & $27.75 \pm 5.62$ & $29.3 \pm 5.3$ & 0.086 & $28.8 \pm 4.9$ & 0.23 \\
BMI & $33.61 \pm 8.96$ & $26.2 \pm 3.7$ & $<\mathbf{0 . 0 0 0 1}$ & $25.9 \pm 3.9$ & $<\mathbf{0 . 0 0 0 1}$ \\
Gestational diabetes, $n / N(\%)$ & $6 / 81(7.4)$ & $4 / 78(5)$ & 0.8 & $5 / 80(6)$ & 0.84 \\
Pre-eclampsia, $n / N(\%)$ & $5 / 81(6.2)$ & $3 / 78(4)$ & 0.45 & $0 / 80(0)$ & $\mathbf{0 . 0 2 7}$ \\
Oligohydramnios, $n / N(\%)$ & $3 / 81(3.7)$ & $16 / 78(21)$ & $\mathbf{0 . 0 0 4 3}$ & $3 / 80(4)$ & 0.96 \\
Placental abruption, $n / N(\%)$ & $0 / 81(0)$ & $5 / 78(6)$ & $\mathbf{0 . 0 5}$ & $0 / 80(0)$ & 1 \\
Spontaneous labor, $n / N(\%)$ & $27 / 81(33.3)$ & $30 / 78(38)$ & $<\mathbf{0 . 0 0 0 1}$ & $11 / 80(14)$ & 0.27 \\
Spontaneous membrane rupture, $n / N(\%)$ & $18 / 81(22.2)$ & $36 / 78(46)$ & $<\mathbf{0 . 0 0 0 1}$ & $6 / 80(8)$ & 0.47 \\
Transfusion requirement, $n / N(\%)$ & $0 / 81(0)$ & $7 / 78(9)$ & $\mathbf{0 . 0 2 1}$ & $1 / 80(1)$ & 0.4 \\
Chorioamnionitis, $n / N(\%)$ & $0 / 81(0)$ & $2 / 78(3)$ & 0.51 & $0 / 80(0)$ & 1 \\
Chorioamniotic membrane separation, $n / N(\%)$ & $0 / 81(0)$ & $20 / 78(26)$ & $<\mathbf{0 . 0 0 0 1}$ & $0 / 80(0)$ & 1 \\
Pulmonary edema, $n / N(\%)$ & $0 / 81(0)$ & $5 / 78(6)$ & 0.06 & $0 / 80(0)$ & 1
\end{tabular}

Bold values indicate $p<0.05$.

Fig. 2. Graphical representation of ambulation status at 30-month follow-up of the UPMC cohort compared to MOMS trial data.

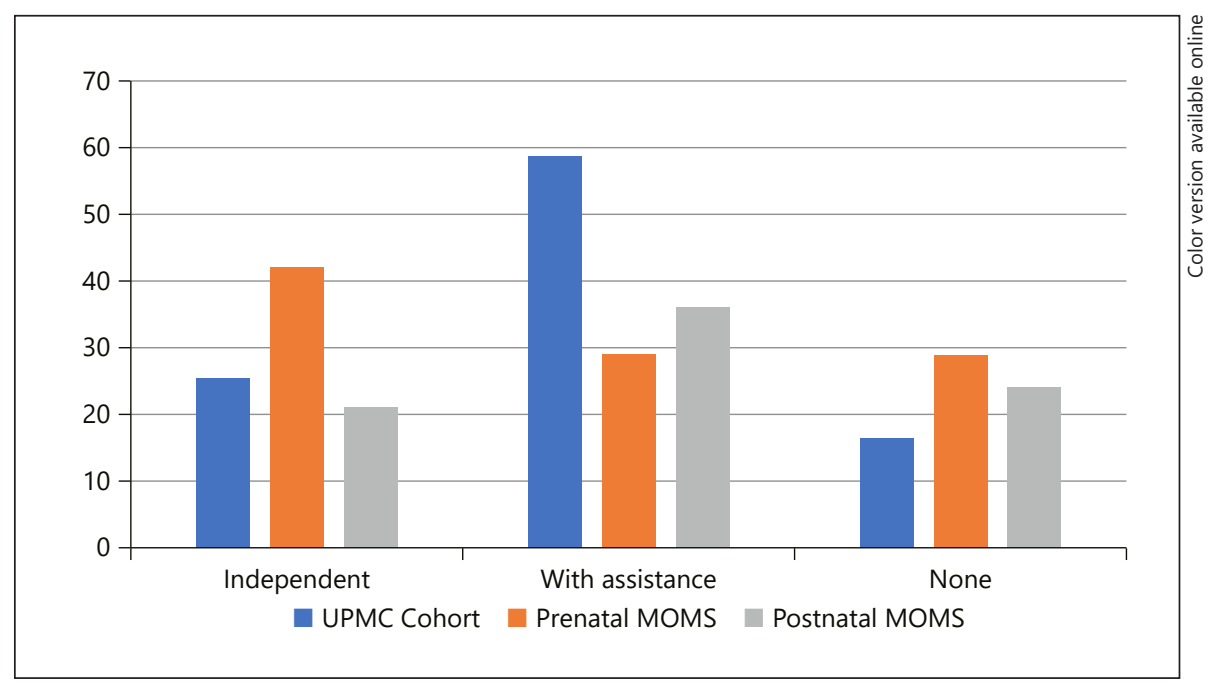

with assistive devices, our cohort had a statistically higher rate of any ambulatory ability (83.7\%) compared to both the prenatal $(71 \% ; p=0.0005)$ and postnatal $(57 \%$; $p<0.0001)$ MOMS cohorts.

We had data on 81 mothers in our data set (Table 4). Among our cohort, $30 \%$ of mothers delivered vaginally, whereas all mothers in the MOMS trial underwent cesarean section. Our cohort also had a higher BMI compared to the postnatal MOMS cohort (33.6 vs. 25.9; $p<0.0001$ ). Because enrollment for randomization in the MOMS trial required a lower BMI, both the prenatal and postnatal cohorts were slimmer. Additionally, $60.5 \%$ of our cohort would have been excluded from the MOMS trial maternal and fetal factors. Compared to the prenatal MOMS group, our cohort had higher BMIs (33.6 vs. $26.2 ; p<0.0001$ ) and statistically significant lower rates of oligohydramnios ( 3.7 vs. $21 \%$; $p=0.004)$, placental abruption ( 0 vs. $6 \%$; $p=0.05)$, spontaneous membrane rupture (22.2 vs. $46 \%$; $p<0.0001)$, and chorioamnionitic membrane separation ( 0 vs. $26 \% ; p<0.0001$ ). Of note, the rate of complications in our cohort of cesarean patients was zero [5].

Lastly, we compared our rates of shunt infection, Chiari II decompression, and tethered cord release, as well as ambulation status, at 12 months to data at the longest follow-up in our institutional cohort to provide information about the durability of results of postnatal surgical 
Fig. 3. Graphical representation of ambulation status at 12 months of the UPMC cohort compared to the longest follow-up.

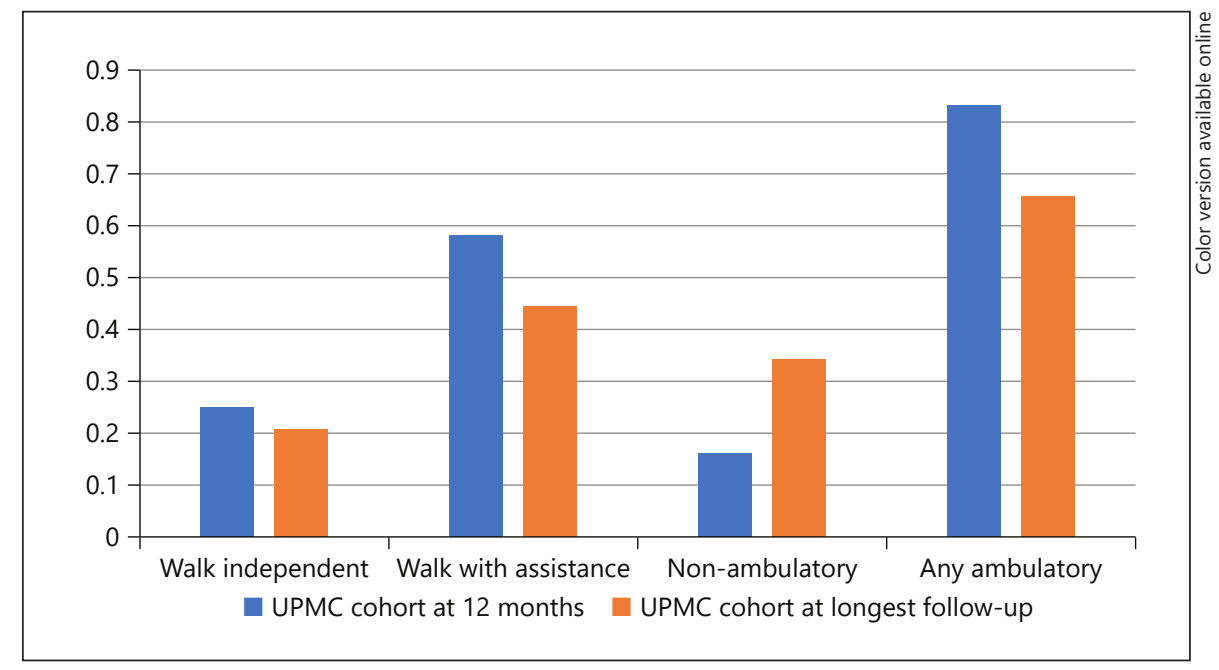

Table 5. Ambulation status for the UPMC cohort at 12 months compared to the longest follow-up

\begin{tabular}{lcrr}
\hline & $\begin{array}{l}\text { UPMC cohort } \\
\text { at } 12 \text { months }\end{array}$ & $\begin{array}{l}\text { UPMC cohort } \\
\text { at longest follow-up }\end{array}$ & $p$ value \\
\hline Shunt infections, $n / N(\%)$ & $14 / 134(10.4)$ & $22 / 134(16.4)$ & 0.35 \\
Chiari II decompression, $n / N(\%)$ & $17 / 163(10.4)$ & $26 / 163(16.0)$ & 0.14 \\
Tethered cord release, $n / N(\%)$ & $3 / 163(1.8)$ & $32 / 163(19.6)$ & $<\mathbf{0 . 0 0 0 1}$ \\
Walk independent, $n / N(\%)$ & $39 / 154(25.3)$ & $32 / 152(21.1)$ & 0.38 \\
Walk with assistance, $n / N(\%)$ & $90 / 154(58.4)$ & $68 / 152(44.7)$ & $\mathbf{0 . 0 1 7}$ \\
Nonambulatory, $n / N(\%)$ & $25 / 154(16.2)$ & $52 / 152(34.2)$ & $\mathbf{0 . 0 0 0 3}$ \\
Any ambulation, $n / N(\%)$ & $129 / 154(83.8)$ & $100 / 152(65.8)$ & $<\mathbf{0 . 0 0 0 1}$ \\
\hline
\end{tabular}

Bold values indicate $p<0.05$.

interventions over time (Table 5; Fig. 3). There was no statistically significant difference in our cohort at 12 months of age compared to the longest follow-up regarding rates of shunt infection or Chiari II decompression. There were 14 shunt infections among our cohort at 12 months (10.4\%/year) and 8 infections from 12 months to the longest follow-up (6\%/year). At the longest follow-up, there was a higher number of tethered cord releases compared to at 12 months of age $(19.6 \%$ vs.; $p<0.0001)$. Regarding ambulation status, there was a decline in ambulation status over time with a statistically significant number of patients being nonambulatory at the longest follow-up. At the most recent follow-up, our cohort demonstrated a decline in any ambulatory status ( 83.8 vs. $65.8 \% ; p<0.0001)$ as well as in the number of patients ambulating with assistance ( 58.4 vs. $44.7 \% ; p=0.017$ ), but not in the rate of independent ambulation (25.3 vs. $21.1 \%$; $p=0.38)$.

\section{Discussion}

The surgical management of myelomeningocele has traditionally been performed during the postnatal period. Recent advances in technology and the publication of the landmark MOMS trial have generated a growing interest in prenatal closure of myelomeningocele. While there appear to be at least short-term benefits with in utero closure such as decreased shunting rates and increased independent ambulatory status, the durability and generalizability of the outcomes remain unknown. The goal of this study was to compare patient outcomes at Children's Hospital of Pittsburgh with the MOMS prenatal and postnatal cohorts. Additionally, we compared our outcomes at 12 months of age to our longest follow-up to begin to examine the question of durability.

For patients with myelomeningoceles, hydrocephalus is common [6-13]. Traditionally, shunting rates in the 
literature have ranged from 57 to $86 \%$ [14-19]. In 2018, Kim et al. [20] reported that the rate of surgical treatment for hydrocephalus in the National Spina Bifida Patient Registry was $79.99 \%$. In the MOMS trial, one of the primary outcomes was shunt placement. They reported a significant decrease in the number of patients who received a shunt by 12 months in the prenatal compared to the postnatal cohort [2]. Our cohort had similar results to the MOMS trial postnatal group, with $85.9 \%$ of our patients being shunted, in comparison with $40 \%$ of the prenatal group and $82 \%$ of the postnatal group [21]. One concern with the MOMS trial is that $72.5 \%$ of prenatal patients met the initial defined criteria for shunt placement, but only $44 \%$ received a shunt [22]. The revised criteria for shunting in the MOMS trial reduced the number of prenatal patients meeting criteria for shunt placement to $49.5 \%$ from the original $72.5 \%$. The authors were concerned that the revised criteria had not been validated to prospectively guide shunt placement in children with spina bifida. Our shunting rates were comparable to those published by Laskay et al. [23], who reported that $84.6 \%$ of their patients required shunt placement. In contrast to the MOMS prenatal cohort, $100 \%$ of patients meeting the MOMS criteria for shunting received a shunt at Laskay's institution. Interestingly, Chakraborty et al. [24] published a study looking at 54 patients who underwent postnatal closure of myelomeningoceles with an average follow-up of 31 months. They used strict criteria for determination of shunt placement (clinical features of raised ICP, including bulging fontanelle, bradycardia, setting sun sign, progressively increasing occipitofrontal head circumference, and increasing ventriculomegaly as documented on serial ultrasound examinations and serial CT) and reported a shunt rate of $51.9 \%$, similar to that reported in the MOMS trial. Again, longer-term data have not been published. Although the CNS guidelines recommend that infants who meet specific criteria should undergo prenatal surgery to reduce the risk of developing shunt-dependent hydrocephalus, it remains unclear whether prenatal surgery or the use of stricter criteria for shunt placement makes the difference in shunting rates. Additional studies will be needed to elucidate this. It has been shown that fetal surgery does not obviate the need for shunt placement if the posterior horn of the lateral ventricle measures $>15 \mathrm{~mm}$ on prenatal ultrasound [25].

The MOMS trial publication identified an increased rate of tethered cord syndrome in patients undergoing prenatal closure, but this increase was not statistically significant (relative risk of $6.15,8 \%$ prenatal closure vs. $1 \%$ postnatal closure, $p=0.06$ ) [2]. Although the data did not

Postnatal Cohort Compared to Postnatal MOMS meet statistical significance, there was at least a trend towards higher rates of tethered cord syndrome with prenatal closure, especially when considering other literature available [26]. There are no long-term data regarding prenatal closure and the development of tethered cord syndrome. In our institutional postnatal cohort, there is a 10 -fold increase in the rate of tethered cord release at 30 months compared to 12 months. One could hypothesize that given our initial rate of tethered cord syndrome of $1.8 \%$ at 12 months and the rate of tethering of $8 \%$ in the prenatal cohort, with longer follow-up, the rate of tethered cord syndrome would become statistically significant between the prenatal and postnatal arms of the MOMS trial. Additional publication analyzing these data from the MOMS trial is needed. We also believe that some of the difference is related to the surgical technique with regard to the prenatal closure group. It has been our experience that prenatal closure results in a less robust reconstruction due to more friable tissue, less distinct tissue layers, and a need for rapid completion of the procedure to minimize fetal risk. We feel that the high rate of wound complications/tethering seen in the MOMS cohort early on is representative to a substantial risk to long-term ambulatory ability. Further, there may be some site-specific differences in holistic management. Our center benefits from a long-standing multidisciplinary spina bifida clinic that focuses on early and preventative interventions across multiple specialties including orthopedic surgery, physical medicine and rehabilitation, and neurosurgery. These all may contribute to a higher rate of functional ambulation preservation over time. Additionally, it should be noted that the MOMS trial manuscript did not clarify whether their tethered cord group only included symptomatic patients or also included those with only radiographic findings.

The rate of Chiari II decompression in patients with myelomeningocele in the National Spina Bifida Patient Registry was 9.15\% [27]. The rate of Chiari II decompression in our cohort was similar (10.4\%). Interestingly, the rate of Chiari II decompression of the postnatal MOMS cohort was only $5 \%$, possibly because the MOMS cohort analyzed data only through 30 months of age. This may also be due to the trend away from Chiari II decompression after 2005, as reported by Kim et al. [27]. Our longterm data suggest that the rate of Chiari II decompression is relatively stable over time $(p=0.14)$. The decreased incidence of hindbrain herniation (64\% prenatal vs. $96 \%$ postnatal), brainstem kinking (20\% prenatal vs. $48 \%$ postnatal), and abnormal location of the fourth ventricle (46\% prenatal vs. $72 \%$ postnatal) with prenatal closure [2] 
are suggestive of the potential for a decreased rate of Chiari II decompression surgery over time, though at this point it is unknown if the surgery has been merely postponed or truly prevented in these patients. Patients that die from Chiari II malformation in infancy ( $3 \%$ of our cohort) have been described on autopsy and postmortem imaging to have brainstem malformations, an early developmental abnormality which is unlikely to be reversed by prenatal surgery $[4,28,29]$. Further research is needed to determine whether the improvement in the radiographic Chiari II malformation seen with prenatal surgery translates to decreased surgery rates for Chiari II malformation over the longer term and decreased perinatal mortality for infants with myelomeningocele treated prenatally.

Motor function and ambulatory status are 2 main outcomes in the MOMS trial [2]. Adzick et al. [2] reported that infants who underwent prenatal closure were more likely to have $2+$ better functional levels compared to anatomic levels ( 32 vs. $12 \%$ ). Moreover, they reported that $42 \%$ of patients prenatally closed were walking independently, compared to only $21 \%$ of the patients in the postnatal closure cohort. Farmer et al. [30] published the full cohort 30-month outcomes of the MOMS trial, reporting that prenatal surgery results in improved functional levels at least twice better than anatomic levels (26.4 vs. $11.4 \%$ ), with improvement in independent ambulation (44.8 vs. 23.9\%). This analysis occurred at 30 months, and longterm data are still pending. Danzer et al. [31] reported in their study of 42 patients who underwent fetal repair via a questionnaire at a median of 10 years that $79 \%$ of patients were community ambulators, $9 \%$ were household ambulators, and 14\% were wheelchair-dependent. Januschek et al. [8] published a retrospective study that included 28 patients with myelomeningocele who underwent postnatal closure and reported that 12 of 16 (75\%) patients older than 2 years of age were ambulatory with/ without assistive devices. In our study, we found that at 30 months, the MOMS prenatal cohort had a higher rate of independent ambulation, but our cohort demonstrated the highest rate of any ambulatory ability of the 3 groups. Our cohort also demonstrated a more favorable anatomic-functional level compared to the prenatal group. This difference may be related to the surgical technique for the same reasons as stated previously, including more friable tissues, less distinct layers, and focus on rapid completion to prevent maternal complications. Early imaging may also be less accurate in predicting the exact level of anatomic involvement. We also compared our cohort at these early time points to our long-term follow-up data, and our cohort's ambulatory function showed a decline from 84 to $66 \%$. There are many reasons for a child to lose ambulatory function such as symptomatic cord tethering as children age and go through grow spurts, lower extremity surgery, or change in body habitus with increasing age; further studies investigating the etiology of this loss of ambulatory ability are needed. It seems likely that similar declines in ambulatory status will occur with the prenatal surgery cohort as their age increases, and if the incidence of tethered cord remains elevated compared to postnatal closure, the decrease in ambulatory status may be higher than anticipated. According to the CNS/AANS/ SBA guidelines, it is not clear at this time "whether prenatal or postnatal repair provides improved ability to ambulate upon reaching adulthood [3]."

One of the main criticisms of the MOMS trial is a concern for generalizability. The outcomes of the trial are based upon strict maternal and fetal inclusion criteria such as "singleton pregnancy, myelomeningocele levels between T12 and S1, evidence of hindbrain herniation, gestational age of 19.0-25.9 weeks at randomization, normal karyotype, and maternal age of $>18$ years." Exclusion criteria included fetal anomaly (unrelated to myelomeningocele), severe kyphosis, risk of preterm birth, placental abruption, BMI of 35 or more, previous hysterotomy in active segment, lack of support person, and inability to comply with travel and follow-up requirements [2]. Laskay et al. [23] discussed the generalizability of the MOMS results compared to their cohort. They reported that only $70.5 \%$ of their patients would have been eligible for the MOMS trial, which is slightly higher than our reported percentage of $60.5 \%$. The sociodemographic factors in their cohort which differed from the MOMS trial included younger age and fewer mothers who were married or living with a partner. At their institution, they did not routinely obtain a karyotype or a fetal MRI. Our cohort of mothers also differed from the MOMS trial mothers in that the BMI of our patients were statistically significantly higher compared to both arms of the MOMS trial. Obesity is a significant concern in terms of accessing and positioning the uterus for safe intraoperative closure of myelomeningocele, and thus results in technical limitations of the procedure except perhaps with the use of endoscopy. Additionally, obesity is an independent surgical risk factor for women undergoing elective major surgery. With more centers performing fetal closure of myelomeningoceles, it will be interesting to see whether relaxing the original strict inclusion criteria will alter the published outcomes.

Lastly, there remains disagreement regarding the optimal mode of delivery for patients with myelomeningoceles. 
Cesarean sections are required for fetal surgery mothers in the current pregnancy as well as subsequent pregnancies in the MOMS trial, and there is an elevated risk profile compared to vaginal delivery for those women undergoing fetal surgery [32]. Greene et al. [5] published that mode of delivery (vaginal vs. cesarean) had no effect on shunt rate, Chiari II decompression, anatomic-functional level, or ambulation status. Thus, the mothers are undergoing 2 major surgeries for the fetal surgery pregnancy alone, and cesarean section for all subsequent pregnancies, when vaginal delivery is safe for the mother and does not harm the infant. Nearly all of the risk of fetal surgery is borne by the mother, and all of the benefit is to the child.

In conclusion, while the outcomes at early time points in the MOMS trial are encouraging, there are still several unknowns regarding long-term outcomes and overall generalizability of the data. Moreover, the risks to the mother and fetus remain a concern. This single-institutional retrospective study suggests that the difference between the outcomes of prenatal and postnatal closure of myelomeningocele may not be as dramatic over the longer term.

\section{Statement of Ethics}

This research has been approved by our IRB committee. The reference number is PRO8120394.

\section{Conflict of Interest Statement}

The authors have no personal or institutional conflicts of interest with regard to the authorship and/or publication of this manuscript.

\section{Funding Sources}

This research received no specific grant from any funding agency in the public, commercial, or not-for-profit sectors.

\section{Author Contributions}

K.W., M.M., and S.G. were involved in the design and conception of this manuscript. K.W., M.M., M.D.W., and S.G. performed the literature search. K.W., M.M., and M.D.W. compiled the primary manuscript. K.W., M.M., and M.D.W. compiled the tables/ figures. Z.T., N.Z., C.P., C.B., S.J., and S.G. critically revised the manuscript. All authors have approved the manuscript as it is written.

\section{References}

1 Bruner JP, Tulipan N, Paschall RL, Boehm FH, Walsh WF, Silva SR, et al. Fetal surgery for myelomeningocele and the incidence of shunt-dependent hydrocephalus. JAMA. 1999;282(19):1819-25.

2 Adzick NS, Thom EA, Spong CY, Brock JW 3rd, Burrows PK, Johnson MP, et al. A randomized trial of prenatal versus postnatal repair of myelomeningocele. N Engl J Med. 2011;364(11):993-1004.

3 Mazzola CA, Assassi N, Baird LC, Bauer DF, Beier AD, Blount JP, et al. Congress of neurological surgeons systematic review and evidence-based guidelines for pediatric myelomeningocele: executive summary. Neurosurgery. 2019;85(3):299-301.

4 McDowell MM, Blatt JE, Deibert CP, Zwagerman NT, Tempel ZJ, Greene S. Predictors of mortality in children with myelomeningocele and symptomatic Chiari type II malformation. J Neurosurg Pediatr. 2018;21(6):587-96.

5 Greene S, Lee PS, Deibert CP, Tempel ZJ, Zwagerman NT, Florio K, et al. The impact of mode of delivery on infant neurologic outcomes in myelomeningocele. Am J Obstet Gynecol. 2016;215(4):495.

6 Burmeister R, Hannay HJ, Copeland K, Fletcher JM, Boudousquie A, Dennis M. Attention problems and executive functions in children with spina bifida and hydrocephalus. Child Neuropsychol. 2007;11(3):265-83.
7 Elgamal EA. Natural history of hydrocephalus in children with spinal open neural tube defect. Surg Neurol Int. 2012;3:112.

8 Januschek E, Röhrig A, Kunze S, Fremerey C, Wiebe B, Messing-Jünger M. Myelomeningocele: a single institute analysis of the years 2007 to 2015. Childs Nerv Syst. 2016;32(7): 1281-7.

9 Morota N, Ihara S. Postnatal ascent of the cerebellar tonsils in Chiari malformation type II following surgical repair of myelomeningocele. J Neurosurg Pediatr. 2008;2(3):188-93.

10 Radcliff E, Cassell CH, Laditka SB, Thibadeau JK, Correia J, Grosse SD, et al. Factors associated with the timeliness of postnatal surgical repair of spina bifida. Childs Nerv Syst. 2016; 32(8):1479-87.

11 Vinck A, Maassen B, Mullaart R, Rotteveel J. Arnold-Chiari-II malformation and cognitive functioning in spina bifida. J Neurol Neurosurg Psychiatry. 2006;77(9):1083-6.

12 Wiedenbauer G, Jansen-Osmann P. Spatial knowledge of children with spina bifida in a virtual large-scale space. Brain Cogn. 2006; 62(2):120-7.

13 Yeates KO, Loss N, Colvin AN, Enrile BG. Do children with myelomeningocele and hydrocephalus display nonverbal learning disabilities? An empirical approach to classification. J Int Neuropsychol Soc. 2003;9(4):653-62.
14 Bowman RM, Boshnjaku V, McLone DG. The changing incidence of myelomeningocele and its impact on pediatric neurosurgery: a review from the Children's Memorial Hospital. Childs Nerv Syst. 2009;25(7):801-6.

15 Bowman RM, McLone DG, Grant JA, Tomita T, Ito JA. Spina bifida outcome: a 25-year prospective. Pediatr Neurosurg. 2001;34(3):11420.

16 Kshettry VR, Kelly ML, Rosenbaum BP, Seicean A, Hwang L, Weil RJ. Myelomeningocele: surgical trends and predictors of outcome in the United States, 1988-2010. J Neurosurg Pediatr. 2014;13(6):666-78.

17 Marreiros H, Loff C, Calado E. Who needs surgery for pediatric myelomeningocele? A retrospective study and literature review. J Spinal Cord Med. 2015;38(5):626-40.

18 Mayer S, Weisser M, Till H, Gräfe G, Geyer C. Congenital myelomeningocele: do we have to change our management? Cerebrospinal Fluid Res. 2010;7:17.

19 Schoenmakers MA, Uiterwaal CS, Gulmans VA, Gooskens RH, Helders PJ. Determinants of functional independence and quality of life in children with spina bifida. Clin Rehabil. 2005;19(6):677-85.

20 Kim I, Hopson B, Aban I, Rizk EB, Dias MS, Bowman R, et al. Treated hydrocephalus in individuals with myelomeningocele in the national spina bifida patient registry. J Neurosurg Pediatr. 2018;22(6):646-51. 
21 Kellogg R, Lee P, Deibert CP, Tempel Z, Zwagerman NT, Bonfield CM, et al. Twenty years' experience with myelomeningocele management at a single institution: lessons learned. J Neurosurg Pediatr. 2018;22(4): 439-43.

22 Tulipan N, Wellons JC 3rd, Thom EA, Gupta N, Sutton LN, Burrows PK, et al. Prenatal surgery for myelomeningocele and the need for cerebrospinal fluid shunt placement. J Neurosurg Pediatr. 2015;16(6):613-20.

23 Laskay NMB, Arynchyna AA, McClugage SG, Hopson B, Shannon C, Ditty B, et al. A comparison of the MOMS trial results to a contemporaneous, single-institution, postnatal closure cohort. Childs Nerv Syst. 2017;33(4): 639-46.

24 Chakraborty A, Crimmins D, Hayward R, Thompson D. Toward reducing shunt placement rates in patients with myelomeningocele. J Neurosurg Pediatr. 2008;1(5):361-5.
25 Tulipan N, Wellons JC 3rd, Thom EA, Gupta N, Sutton LN, Burrows PK, et al. Prenatal surgery for myelomeningocele and the need for cerebrospinal fluid shunt placement. J Neurosurg Pediatr. 2015;16(6):613-20.

26 Mazzola CA, Albright AL, Sutton LN, Tuite GF, Hamilton RL, Pollack IF. Dermoid inclusion cysts and early spinal cord tethering after fetal surgery for myelomeningocele. $\mathrm{N}$ Engl J Med. 2002;347(4):256-9.

27 Kim I, Hopson B, Aban I, Rizk EB, Dias MS Bowman R, et al. Decompression for Chiari malformation type II in individuals with myelomeningocele in the national spina bifida patient registry. J Neurosurg Pediatr. 2018; 22(6):652-8.

28 Shinde S, Singhal S. Meningomyelocele: the tip of the iceberg. BMJ Case Rep. 2009;2009: bcr04.2009.1811.

29 Griffiths PD, Wilkinson ID, Variend S, Jones A, Paley MN, Whitby E. Differential growth rates of the cerebellum and posterior fossa assessed by post mortem magnetic resonance imaging of the fetus: implications for the pathogenesis of the chiari 2 deformity. Acta Radiol. 2004;45(2):236-42.

30 Farmer DL, Thom EA, Brock JW 3rd, Burrows $\mathrm{PK}$, Johnson MP, Howell LJ, et al. The management of Myelomeningocele Study: full cohort 30-month pediatric outcomes. Am J Obstet Gynecol. 2018;218:256.e1-e13.

31 Danzer E, Thomas NH, Thomas A, Friedman $\mathrm{KB}$, Gerdes M, Koh J, et al. Long-term neurofunctional outcome, executive functioning, and behavioral adaptive skills following fetal myelomeningocele surgery. Am J Obstet Gynecol. 2016;214(2):269.

32 Goodnight $\mathrm{WH}$, Bahtiyar O, Bennett KA, Emery SP, Lillegard JB, Fisher A, et al. Subsequent pregnancy outcomes after open maternal-fetal surgery for myelomeningocele. Am J Obstet Gynecol. 2019;220:494 